\title{
Effect of Different Phosphorus Precursors on Biomimetic Hydroxyapatite Powder Properties
}

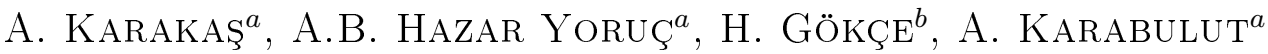 \\ AND D. CEYLAN ERDOĞAN ${ }^{a}$ \\ ${ }^{a}$ Science and Technology Application and Research Center, Yildiz Technical University, 34349, Istanbul, Turkey \\ ${ }^{b}$ Metallurgical and Materials Engineering, Istanbul Technical University, 34469, Istanbul, Turkey
}

\begin{abstract}
Hydroxyapatite is the main component of natural hard tissues, such as teeth and bone. It has been studied extensively as a candidate biomaterial for its use in prosthetic applications. Hydroxyapatite was formulated as $\mathrm{Ca}_{10}\left(\mathrm{PO}_{4}\right)_{6}(\mathrm{OH})_{2}$ and it has a high stability under physiological conditions. Also hydroxyapatite can be synthesized using different calcium and phosphorus precursors. In this study, biomimetic hydroxyapatite powder has been synthesized simulating physiological conditions. Synthetic body fluids which have the same composition as human blood plasma instead of pure water were used as precipitation media to obtain biological conditions. Recent research involved the effect of different Ca-precursors however aim of this study is to determine the effect of phosphorus resources. In this study, the synthesis of hydroxyapatite powder is carried out by using biomimetic method in synthetic body fluids. Calcium acetate $\left[\mathrm{Ca}\left(\mathrm{CH}_{3} \mathrm{COO}\right)_{2}, \mathrm{CA}\right]$ and diammonium hydrogen phosphate $\left[\left(\mathrm{NH}_{4}\right)_{2} \mathrm{HPO}_{4}, \mathrm{DAHP}\right]$, ammonium dihydrogen phosphate $\left[\mathrm{NH}_{4} \mathrm{H}_{2} \mathrm{PO}_{4}, \mathrm{ADHP}\right]$, dipotassium hydrogen phosphate $\left[\mathrm{K}_{2} \mathrm{HPO}_{4}, \mathrm{DPHP}\right]$ and orthophosphoric acid $\left[\mathrm{H}_{3} \mathrm{PO}_{4}, \mathrm{OPA}\right]$ were used as Ca- and P-precursors. Chemical structures of synthesized powders have been examined by Fourier transform infrared and X-ray diffraction. Results showed that synthesized powders have a pure hydroxyapatite structure. However, ADHP precursors have an unfavorable effect on sintered hydroxyapatite powders. Using ADHP phase transition was caused in pure hydroxyapatite structure and apatite and whitlockite were observed as secondary phases. Their particle size, surface area determination and morphological structures have been characterized by Zeta-Sizer, biomimetic hydroxyapatite the Brunauer-Emmett-Teller analysis and scanning electron microscopy images, respectively. As a result different starting materials have affected the structure, particle size and morphological properties of biomimetic hydroxyapatite.
\end{abstract}

DOI: $10.12693 /$ APhysPolA.123.418

PACS: 87.85.J-

\section{Introduction}

Hydroxyapatite $\left[\mathrm{Ca}_{10}\left(\mathrm{PO}_{4}\right)_{6}(\mathrm{OH})_{2}, \mathrm{HA}\right]$ has been used for decades as a biomaterial in orthopedic and dental applications due to its biocompatibility and similarity to the inorganic components of bone and teeth in human [1]. Apatite used in biomedical applications mostly has a $\mu \mathrm{m}$ - or nanometer-size. There are a lot of techniques such as precipitation, hydrothermal, sol-gel, crystal conversion, microwave techniques and nanoindentation etc. to synthesize HA. Because it is easy and economic, precipitation method is the most common technique [2]. Also precipitation method can be classified as a biomimetic [3] and chemical precipitation [4]. The main difference between biomimetic and chemical methods in addition to $\mathrm{pH}$ and synthesis temperature is preparation media. Water and simulated body fluids were preferred as a precipitation solution for chemical synthesis (CS) and biomimetic synthesis (BS), respectively. Also CS has occurred at highly alkaline media and room temperature compared with BS $\left(7.4 \mathrm{pH}\right.$ and $\left.37^{\circ} \mathrm{C}\right)$. The surface properties and synthesis conditions of calcium hydroxyapatite prepared by using distilled pure water in highly alkaline solution have been studied in different solutions including synthetic body fluids (SBF). Moreover the chemical synthesis of HA powders has been examined by using biomimetic method with the purpose of synthesis of more stable and biocompatible HA powders [3]. However, HA precipitation was carried out in highly alkaline media in all techniques. Furthermore $\mathrm{Ca}\left(\mathrm{NO}_{3}\right)_{2} \cdot 4 \mathrm{H}_{2} \mathrm{O}, \mathrm{Ca}(\mathrm{OH})_{2}$, $\left(\mathrm{NH}_{4}\right)_{2} \mathrm{HPO}_{4}$, and $\mathrm{H}_{3} \mathrm{PO}_{4}$ are the most common precursors to synthesize HA. Unfortunately, according to experimental results we observed that these precursors cause an increase of the $\mathrm{pH}$ of the media.

In the present study as a calcium precursor $\mathrm{Ca}\left(\mathrm{CH}_{3} \mathrm{COO}\right)_{2}$ and as phosphorus precursors $\left(\mathrm{NH}_{4}\right)_{2} \mathrm{HPO}_{4}, \mathrm{NH}_{4} \mathrm{H}_{2} \mathrm{PO}_{4}, \mathrm{~K}_{2} \mathrm{HPO}_{4}$ and $\mathrm{H}_{3} \mathrm{PO}_{4}$ have been used. During the HA synthesis, biomimetic method and physiologic conditions $\left(7.4 \mathrm{pH}\right.$ and $\left.37^{\circ} \mathrm{C}\right)$ have synthesised HA powder. Structural analysis was performed by using X-ray diffraction (XRD) and Fourier transform infrared (FTIR) methods, morphology of the powders were investigated by scanning electron microscopy (SEM) and compared with each other. Also thermal stability, surface area, particle size and density was determined by using thermogravometric/differential thermal analysis (TG/DTA), Brunauer-Emmett-Teller (BET) method, Zeta-Sizer and ultrapicnometer.

\section{Materials and methods}

The SBF solution prepared by Othsuki et al. [5] offered cleaning procedure to obtain more stabilized SBF solutions. For that purpose each material (such as beaker, 
flask etc.) were cleaned according to Othsuki's recipient. SBF solutions were prepared according to Tas's SBF solution [6]. The reagents used to prepare one liter of $\mathrm{SBF}$ are $\mathrm{NaCl}(6.547 \mathrm{~g} / \mathrm{L}, 99.5 \%), \mathrm{NaHCO}_{3}(2.268 \mathrm{~g} / \mathrm{L}$, $99.5 \%), \quad \mathrm{KCl}(0.373 \mathrm{~g} / \mathrm{L}, 99.0 \%), \quad \mathrm{Na}_{2} \mathrm{HPO}_{4} \cdot 2 \mathrm{H}_{2} \mathrm{O}$ (0.178 g/L, 99.5\%), $\mathrm{MgCl}_{2} \cdot 6 \mathrm{H}_{2} \mathrm{O}(0.305 \mathrm{~g} / \mathrm{L}, 99.0 \%)$, $\mathrm{CaCl}_{2} \cdot \mathrm{H}_{2} \mathrm{O}(0.355 \mathrm{~g} / \mathrm{L}, 99.0 \%), \mathrm{Na}_{2} \mathrm{SO}_{4}(0.355 \mathrm{~g} / \mathrm{L}$, $99 \%),\left(\mathrm{CH}_{2} \mathrm{OH}\right)_{3} \mathrm{CNH}_{2}(6.057 \mathrm{~g} / \mathrm{L}, 99.5 \%)$, and $\mathrm{HCl}$ (37 vol.\%). All reagents were purchased from Merck. Reagents were added one by one after each reagent was completely dissolved in water with given order. Also after $\mathrm{MgCl}_{2} \cdot 6 \mathrm{H}_{2} \mathrm{O}$ and $\left(\mathrm{CH}_{2} \mathrm{OH}\right)_{3} \mathrm{CNH}_{2}$ was dissolved, desired amount of $1 \mathrm{M} \mathrm{HCl} \mathrm{(37} \mathrm{wt \%} \mathrm{Merck)} \mathrm{solution} \mathrm{was} \mathrm{added}$ to adjust $\mathrm{pH}$ value $7.4[6]$.

Calcium acetate $\left[\mathrm{Ca}\left(\mathrm{CH}_{3} \mathrm{COO}\right)_{2}, \mathrm{CA}\right]$ and diammonium hydrogen phosphate $\left[\left(\mathrm{NH}_{4}\right)_{2} \mathrm{HPO}_{4}, \mathrm{DAHP}\right]$, ammonium dihydrogen phosphate $\left[\mathrm{NH}_{4} \mathrm{H}_{2} \mathrm{PO}_{4}, \mathrm{ADHP}\right]$, dipotassium hydrogen phosphate $\left[\mathrm{K}_{2} \mathrm{HPO}_{4}, \mathrm{DPHP}\right]$ and orthophosphoric acid $\left[\mathrm{H}_{3} \mathrm{PO}_{4}\right.$, OPA] were supplied from Sigma-Aldrich and used as calcium and phosphorus precursors. Firstly, 0.167 M CA and 0.1561 M DAHP solutions were prepared in SBF. Then DAHP solutions were added to $\mathrm{CA}$ solution with $4 \mathrm{~mL} / \mathrm{dk}$ addition ratio. The final suspension was called S1. The same experiments were also carried out using other $\mathrm{Ca}$ and $\mathrm{P}$ precursors and final suspensions were called $\mathrm{S} 2, \mathrm{~S} 3$, and $\mathrm{S} 4$, respectively. $\mathrm{Ca} / \mathrm{P}$ ratio of $\mathrm{HA}$ in all suspensions was calculated as 1.67. Finally, these suspensions were aged for a day at $37^{\circ} \mathrm{C}$. Following the aging process precipitates was filtered and washed with ultrapure water. The resulting precipitates were dried at $80^{\circ} \mathrm{C}$ for $8 \mathrm{~h}$ and then ground using agate mortar. Dried powders were sintered in air atmosphere at $900{ }^{\circ} \mathrm{C}$ for $2 \mathrm{~h}$ with $10^{\circ} \mathrm{C} / \mathrm{min}$ heat rate in a kiln oven (Protherm). Heat treated powders was called S1S, S2S, S3S, and S4S, respectively.

Chemical structures of synthesized powders have been examined by FTIR (Perkin-Elmer Spectrum-100) and XRD (Shimadzu, XRD-2000, TUBITAK, MAM). Surface area measurements and morphological structures have been characterized by using BET (Quardrosorb SI, Malvern) method and SEM (JEOL-JSM-6335F, TUBITAK, MAM) analysis, respectively. Also ultrapicnometer (Quardrosorb Ultrapyc 1200e, Malvern) was used to measure the density of dried and sintered powders.

\section{Result and discussion}

Figure 1 shows the FTIR spectra of dried and sintered powders. $\mathrm{OH}^{-}$at $3580 \mathrm{~cm}^{-1}$ and $\mathrm{PO}_{4}^{3-}$ at $630 \mathrm{~cm}^{-1}$ are peaks characteristic of HA structure. However, band position of $\mathrm{OH}^{-}$was not clearly seen in Fig. 1 because of its low concentration in the structure. Also $1020 \mathrm{~cm}^{-1}$, $960 \mathrm{~cm}^{-1}$ and $1093 \mathrm{~cm}^{-1}$ peaks are referred to $\mathrm{PO}_{4}^{3-}$ groups in the HA. A very small hump at the wave number $1454 \mathrm{~cm}^{-1}$ in this figure arose from vibrations of $\mathrm{CO}_{3}^{2-}$ ions resulting from dissolution of air $\mathrm{CO}_{2}$ in the hydroxyapatite structure. Also it can be clearly seen that carbonate peaks become insignificant with sintered powders which means that $\mathrm{CO}_{3}^{2-}$ has very weak attractions with the HA structure.

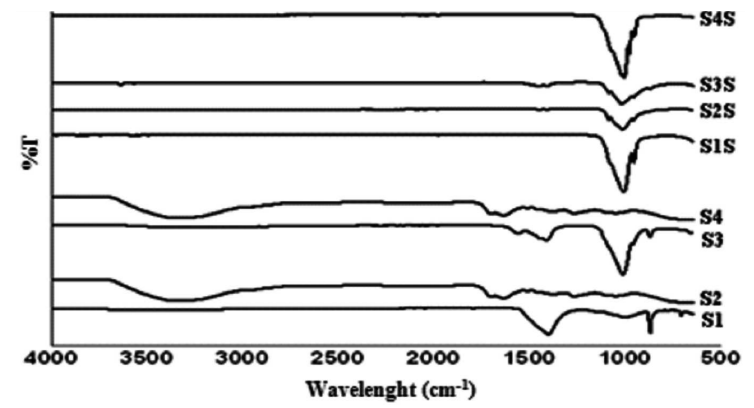

Fig. 1. The FTIR spectrum of dried samples at $80^{\circ} \mathrm{C}$ (S1, S2, S3, S4) and sintered samples at $900^{\circ} \mathrm{C}(\mathrm{S} 1 \mathrm{~S}$, S2S, S3S, S4S).

Figure 2 shows the XRD patterns of HA powders. HA peaks occurred at $2 \theta$ of $28^{\circ}$ and $32^{\circ}$, which are consistent with the standard XRD peaks for HA. The XRD patterns of all the samples indicate that the main phase is HA. Even if literature said that HA could be synthesized with some impurities at initial $\mathrm{pH}$ values higher than 10 , our previous study [7] has proved that HA can be synthesized at low $\mathrm{pH}$ to compare with the literature [8]. Moreover present study is supported that observation and HA was produced at initial $\mathrm{pH} 8.0$ in a low temperature. Also XRD patterns of synthesized amorphous HA structure could be turned to crystalline phase when it sintered at higher temperature without any or negligible transition. However with the high sintering temperatures, HA structure can be decomposed as seen in Fig. 2. Sample S4 has apatite $\left[\mathrm{Ca}_{5}\left(\mathrm{PO}_{4}\right)_{3} \mathrm{Cl}\right]$ and whitlockite $\left[\mathrm{Ca}_{3}\left(\mathrm{PO}_{4}\right)_{2}\right]$ as secondary phases. However S1, S2, S3, S4, S1S, S2S and $\mathrm{S} 4 \mathrm{~S}$ had a pure HA structure. These observations showed that precursors could affected the final purity of synthesized HA at high temperature.

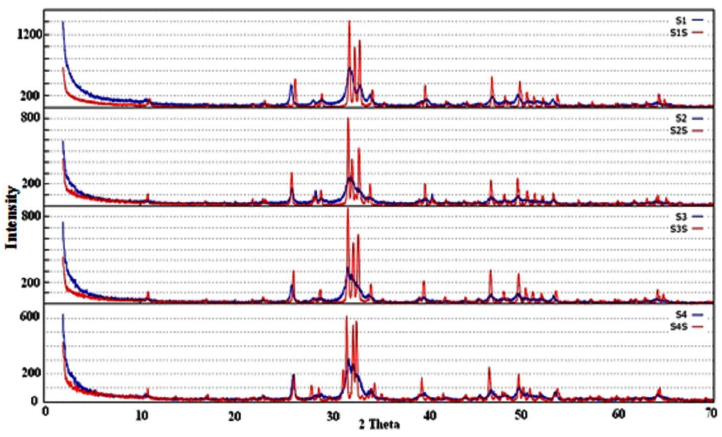

Fig. 2. XRD spectrum of HA samples S1, S2, S3 and $\mathrm{S} 4$ at $80^{\circ} \mathrm{C}$-dried and S1S, S2S, S3S and S4S at $900^{\circ} \mathrm{C}$ -sintered.

SEM micrographs of $80^{\circ} \mathrm{C}$-dried and $900^{\circ} \mathrm{C}$-sintered samples were given in Fig. 3. These powders showed a significant level of agglomeration without heat treatment 
at $900{ }^{\circ} \mathrm{C}$. However $\mathrm{S} 1$ powder had very fine particles when it was compared with the other powders. On the other hand, S1S (Fig. 3b) and S2S (Fig. 3d) samples had more regular and rod-like structure unlike the irregular structure of S3S (Fig. 3f) powders. Moreover, whitlockite phase in the $\mathrm{S} 4 \mathrm{~S}$ structure was seen as a worm shape in the SEM image in Fig. 3h.

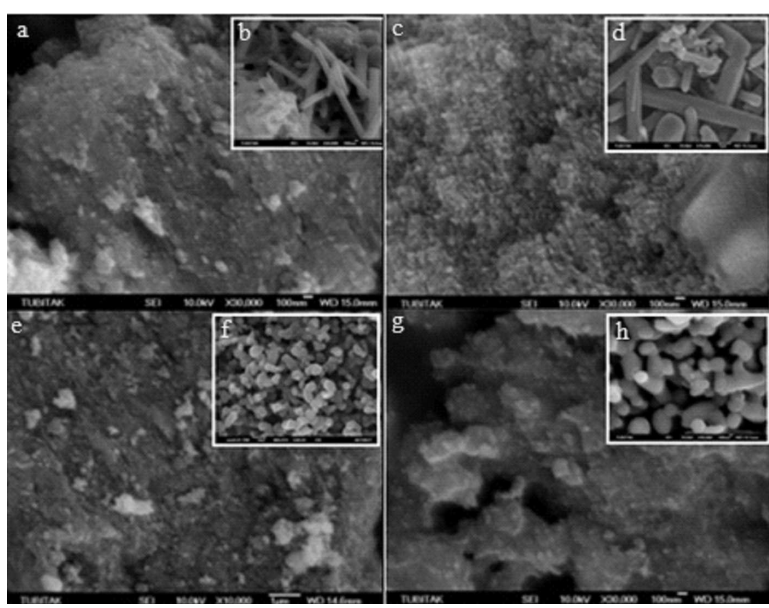

Fig. 3. SEM micrographs of synthesized powders (a) S1 at $80^{\circ} \mathrm{C}$-dried, (b) S1S at $900^{\circ} \mathrm{C}$-sintered, (c) S2 at $80^{\circ} \mathrm{C}$-dried, (d) $\mathrm{S} 2 \mathrm{~S}$ at $900{ }^{\circ} \mathrm{C}$-sintered, (e) $\mathrm{S} 3$ at $80^{\circ} \mathrm{C}$-dried, (f) S3S at $900^{\circ} \mathrm{C}$-sintered, (g) S4 at $80^{\circ} \mathrm{C}$ -dried, (h) S4S at $900^{\circ} \mathrm{C}$-sintered.

TABLE

Surface area, density and particle size values of green and sintered samples.

\begin{tabular}{c|c|c|c}
\hline \hline Sample & $\begin{array}{c}\text { Surface area } \\
{\left[\mathrm{m}^{2} / \mathrm{g}\right]}\end{array}$ & $\begin{array}{c}\text { Density } \\
{\left[\mathrm{g} / \mathrm{cm}^{3}\right]}\end{array}$ & $\begin{array}{c}\text { Particle size } \\
{[\mathrm{nm}]}\end{array}$ \\
\hline S1 & 158.134 & 2.70 & 12 \\
S2 & 115.131 & 2.93 & 16.5 \\
S3 & 87.707 & 2.88 & 21.7 \\
S4 & 102.076 & 2.92 & 18.6 \\
S1S & 3.049 & 3.07 & 622.8 \\
S2S & 2.895 & 3.28 & 655.9 \\
S3S & 1.131 & 3.20 & 1678.8 \\
S4S & 3.727 & 3.24 & 509.6
\end{tabular}

Table shows the specific surface area of the powders. According to these measurements mean size of the HA particles was calculated by the following equation [9]:

particle size $=6 /\left(\rho S_{\mathrm{BET}}\right)$,

where the $\rho$ is the density of the pure HA sample $\left(3.16 \mathrm{~g} / \mathrm{dm}^{3}\right)$ and $S$ refers to specific surface area of powders obtained from BET method. The results showed that particle size of all dried samples was the nanometer scale and powders could be densification of the powders could be increased with heat treatment at high temperature.

\section{Conclusion}

Nano-sized and chemically homogeneous hydroxyapatite powders have been precipitated by using calcium acetate with diammonium hydrogen phosphate, ammonium dihydrogen phosphate, dipotassium hydrogen phosphate and orthophosphoric acid in $\mathrm{SBF}$, at the physiological and biomimetic conditions of $\mathrm{pH} 8.0$ and $37^{\circ} \mathrm{C}$. Except of DPHP all P-precursors would be able to produce pure HA structure at high temperature. It was concluded that different phosphorus precursors affect the HA structure and using different $\mathrm{Ca}$ - and $\mathrm{P}$-precursor combinations could be a useful method to obtain such samples with appropriate properties. Also this study proved that higher $\mathrm{pH}$ values are not necessary to obtain pure HA. In the literature there is any study that is focused on synthesis $\mathrm{HA}$ at low $\mathrm{pH}$ values. As a result this study has proved that HA powders could be possibly synthesised at low $\mathrm{pH}$ values and it is a promising technique to obtain more biocompatible HA structure for biomedical applications. Recent researches will be focused on the studies of mechanical (elasticity modulus, fracture toughness etc.) and biological properties (in vitro toxicity, in vivo behavior) of HA bioceramics.

\section{Acknowledgments}

This study was supported, in part, by the Turkish Scientific and Technical Research Foundation (TUBITAK) within the scope of the project number 110M182 and by the Yildiz Technical University, Science and Technology Application and Research Center.

\section{References}

[1] C. Garcia, C. Garcia, C. Paucar, Inorg. Chem. Commun. 20, 90 (2012)

[2] S. Saber-Samandari, K.A. Gross, Acta Biomater. 5 , 2206 (2009)

[3] A.C. Tas, Biomaterials 21, 1429 (2000)

[4] C.D. Smith, E.F. Jones, in: Shock Compression of Condensed Matter-2001, Eds. M.D. Furnish, AIP Conference Proceedings 620, American Institute of Physics, Melville, NY 2002, p. 651.

[5] C. Ohtsuki, T. Miyazaki, M. Kamitakahara, M. Tanihara, J. Eur. Ceram. Soc. 27, 1527 (2007)

[6] A.C. Tas, Turkish Patent Institute No. 99/0037 (11 January 1997).

[7] A. Karakas, A.B. Hazar Yoruc, D. Ceylan Erdoğan, M. Doğan, Acta Phys. Pol. A 121, 236 (2012).

[8] S.J. Roll, Bachelor Thesis, National Ins. of Tech., Rourkela.

[9] M. Goubin, L.Y. Xiang, Crystal Growth Design 9, 2991 (2009). 